\title{
Experimental and Numerical Investigation of Temperature Distribution on Reactor Pressure Vessel Support under Operating Conditions
}

\author{
Longkun He, ${ }^{1}$ Ying $^{\mathrm{Lv}{ }^{2} \text { and Pengfei Liu }{ }^{1}}{ }^{1}$ \\ ${ }^{1}$ School of Nuclear Science and Engineering, Shanghai Jiao Tong University, Shanghai 200240, China \\ ${ }^{2}$ Shanghai Nuclear Engineering Research and Design Institute Co., Ltd., Shanghai 200233, China \\ Correspondence should be addressed to Pengfei Liu; pfliu@sjtu.edu.cn
}

Received 20 January 2019; Accepted 1 April 2019; Published 18 April 2019

Academic Editor: Eugenijus Ušpuras

Copyright (C) 2019 Longkun He et al. This is an open access article distributed under the Creative Commons Attribution License, which permits unrestricted use, distribution, and reproduction in any medium, provided the original work is properly cited.

Reactor pressure vessel (RPV) support is a key safety facility which is categorized as Class 1 in the ASME nuclear safety design. The temperature distribution of RPV support is one of the key considerations for the concrete safety contacting with the bottom of the support. So it is necessary for accurate evaluation on the temperature field characteristics of RPV support, especially the bottom of support. This paper investigates the temperature field characteristics of modified RPV support which will be applied to a large advanced pressurized water reactor. A support entity is manufactured in a ratio of 1:1, and its temperature distribution is measured under simulated reactor operating conditions. Numerical simulation is also used to validate the results by the developed CFD model. The results show that under the operating conditions, of which the inlet cooling air temperature is $35.35^{\circ} \mathrm{C}$ and the velocity is $6.25 \mathrm{~m} / \mathrm{s}$, the temperature distribution of modified RPV support bottom is uneven, and the highest temperature is around $38^{\circ} \mathrm{C}$, which is much lower than the demanding design temperature $93.3^{\circ} \mathrm{C}$. Therefore, the design of the modified RPV support is reliable. In addition, the results of numerical simulation agree well with the experimental results with the error less than $\pm 4^{\circ} \mathrm{C}$, which ensures the reliability of the conclusion. The effects of inlet cooling air temperature and velocity on the RPV support temperature distribution are further studied. Both the temperature decrease and velocity increase can reduce the RPV support temperature. But the effect of inlet cooling air temperature is more obvious than inlet cooling air velocity. So the best way to improve air cooling capacity is to decrease the support inlet cooling air temperature. The results can provide a good guidance to the design of RPV support for the subsequent large advanced pressurized water reactor.

\section{Introduction}

As one of the key safety equipment, reactor pressure vessel (RPV) should be absolutely safe and reliable throughout the nuclear power plant life. It is supported by several supports mounted on shielded concrete. The RPV supports are designed to withstand the loads of reactor vessel and main pipe and transfer the loads to the reactor building concrete. So the RPV supports play a vital role on the PRV safety and are directly related to the reactor normal operation and lifetime.

According to American Concrete Association (ACI), the shielded concrete temperature should not exceed $65.5^{\circ} \mathrm{C}$ during normal operation and any long-term operating conditions. The local area (e.g., breakthrough area) should not exceed $93.3^{\circ} \mathrm{C}$. Under accident condition or short term, the shielded concrete temperature should not exceed $176.7^{\circ} \mathrm{C}$ $[3,4]$. So it is necessary to accurately evaluate the RPV support temperature distribution, especially the maximum temperature of support bottom which directly contacts with shielded concrete.

In AP1000, the RPV supports structure is shown in Figure 1 [1] and Figure 2 [2]. It consists of four separate aircooled box structures located under the nozzle, which are uniformly distributed along the shielded wall at $90^{\circ}$. The loads transfer from the nozzle to support through a "shoe" shaped block on the top of support. The support eventually passes the RPV load to the vertical and horizontal parts embedded in the shielded wall concrete. The RPV support bottom is in contact 


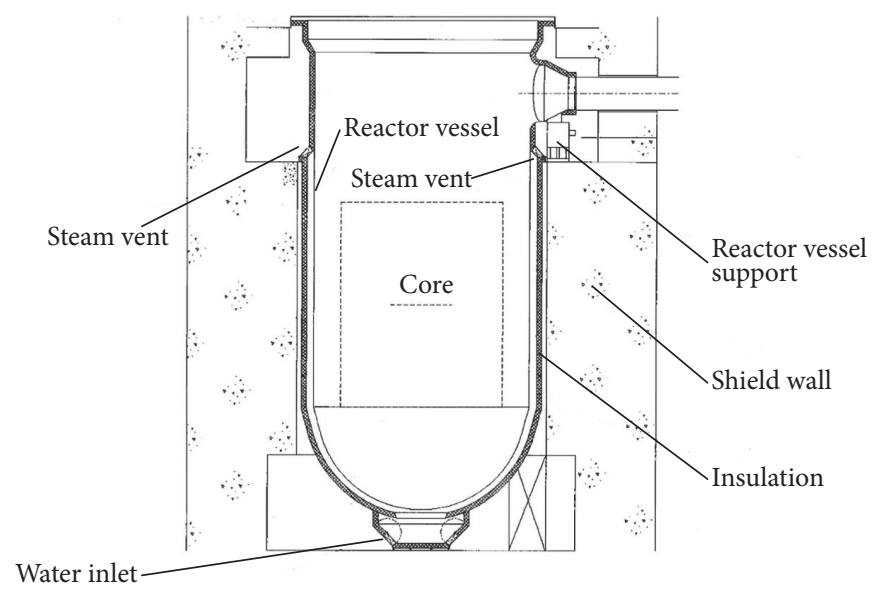

FIGURE 1: AP1000 RPV support layout [1].

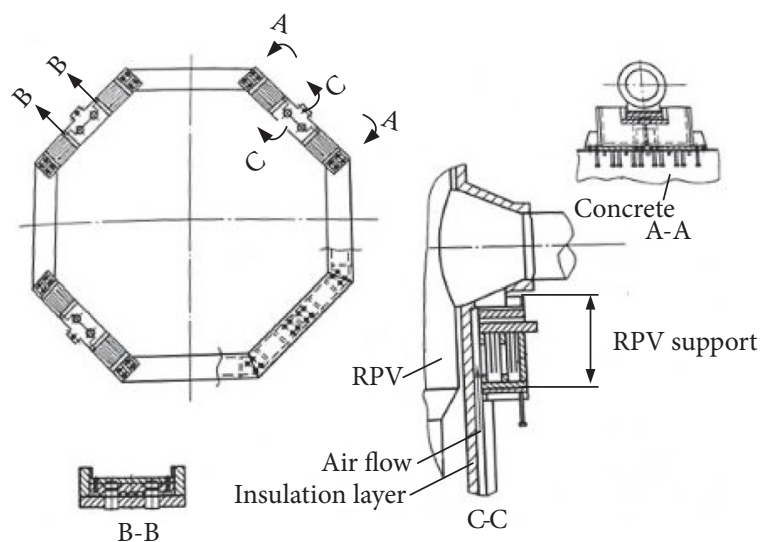

FigURE 2: AP1000 RPV support structure [2].

with the concrete. The temperature of nozzle which contacts support top is about $300^{\circ} \mathrm{C}$. So in order to keep the concrete under the designed temperature of $93.3^{\circ} \mathrm{C}$, the support is cooled by air forced convection which flows through the vertical guide plate and then discharged from the top $[1,2]$. The temperature and velocity of the cooling air will greatly affect the temperature distribution of the support.

Other pressurized water reactors have different support structures. The pressure vessel of APR1400 is supported by four vertical support posts located on the cold leg [5]. The EPR proposed by ARAVE is supported by the system located at the main nozzle [6]. Russia's VVER-1000 pressure vessel is supported by a separate support system located in the horizontal and vertical directions [7].

The design and safety of nuclear power plant components and systems have received much attention. From relatively simple components such as helical tube [8], fuel rods [9], and steam generator drain pipes [10] to the complicated systems such as nuclear coolant pump [11], reactor core support [12, $13]$, shield building [14], and reactor internal $[15,16]$. Both simulation $[9,10,13,14,16]$ and experiments $[11,15,17,18]$ are adopted to verify the applicability of the design and modification for the components and systems.
For RPV support, Anh and Ihn [19] evaluated the structural stiffness of a new plate type support for APR1400 by Finite Element Analysis (FEA) approach. Liao and Liu [20] investigated the effect of inlet air velocity and opening position of middle vertical plate on the highest temperature of support bottom based on numerical simulation and achieved the optimal value of inlet air velocity and opening position of middle vertical plate. Considering the dual goals of support bottom temperature limit and decreasing the inlet air velocity, Liu and Chen [21] achieved the optimal value of inlet air parameter including velocity and temperature by developing the fluid-structure interaction CFD model. Although a few numerical simulation studies related to the RPV support were conducted, the corresponding experiments are almost blank.

This paper verifies the rationality of the modified RPV support design. Compared to AP1000, the support geometry is slightly different, and four cooling fins are added to increase heat dissipation to reduce the temperature of the support bottom. By imitating the actual support cooling conditions in nuclear power plant, a 1:1 ratio of support entity was manufactured to achieve the support temperature distribution, especially the bottom temperature. Further, a fluid-structure interaction CFD model was established by commercial finite element analysis software Fluent to simulate the temperature field and internal air flow field of RPV support and validate with experiments each other. Through the combination analysis of numerical simulation and experiment to investigate the effect of inlet cooling air temperature and velocity on the maximum temperature of support bottom plate, it will provide a good guidance to the design of following large advanced pressurized water reactor support.

\section{Experimental Facility Description}

Figure 3 shows the schematic structure of manufactured RPV support. It is a box-type symmetrical structure, cooled by internal air forced convection. The cooling air enters into the support from the air inlet, flows through the cooling 


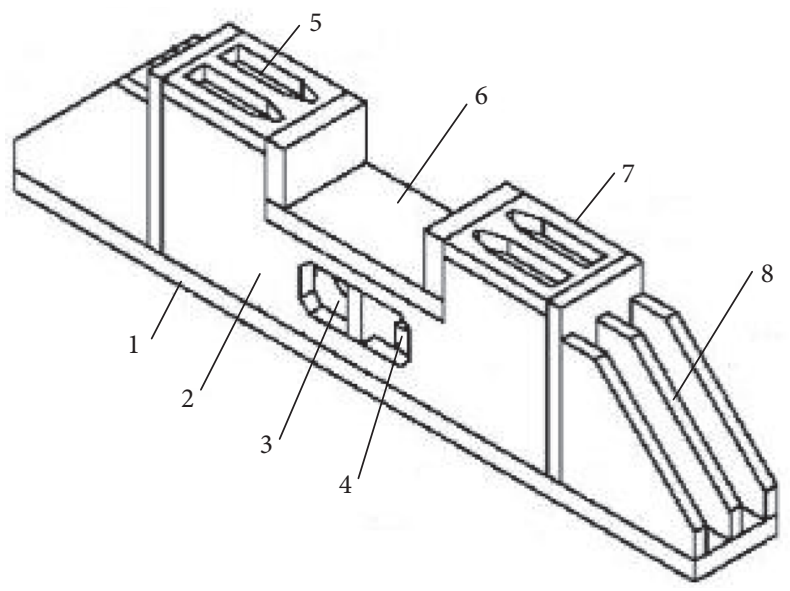

FIGURE 3: The support entity of experiment. 1. Support bottom plate, 2. support front plate, 3. air inlet, 4. cooling fin, 5. air outlet, 6 . heating area, 7 . support back plate, and 8 . rib plate.

TABLE 1: The inlet cooling air parameters for an actual reactor support [22].

\begin{tabular}{lc}
\hline Inlet cooling air parameters & Value \\
\hline Heat loss $(\mathrm{KW})$ & 40 \\
Initial temperature $\left({ }^{\circ} \mathrm{C}\right)$ & 27 \\
Temperature rise causing by heat loss $\left({ }^{\circ} \mathrm{C}\right)$ & 8.35 \\
Final temperature $\left({ }^{\circ} \mathrm{C}\right)$ & 35.35 \\
Velocity $(\mathrm{m} / \mathrm{s})$ & 6.25 \\
\hline
\end{tabular}

fins inside the support, removes heat from the support and exits from the air outlet. The central concave area at the top of the support is in contact with the RPV nozzle, supporting the RPV and transferring the heat load of the nozzle to the support. The support bottom plate is in contact with the concrete, so the maximum temperature of the support bottom needs to be controlled to avoid the concrete overheating. In order to verify the support design effectiveness, an experimental facility was built with the support entity in the ratio of 1:1 simulating the actual operating conditions.

In actual reactor, the cooling air is generated by an air blower and then flows through the reactor cavity and eventually into the RPV support. When flowing through the reactor cavity, the cooling air temperature will rise due to absorb the heat from the insulation layer. For conservative consideration, it is considered that the cooling air completely absorbs the heat loss of the insulation layer when it flows through the reactor cavity. Table 1 lists the inlet air parameters for an actual reactor support [22]. In order to simulate the actual operating conditions, this experiment also uses an air blower to generate cooling air, but omit the reactor cavity, and the cooling air is guided into support by air duct. The velocity of cooling air during experiments can be adjusted by air blower and the temperature is controlled by an air heater so that they are consistent with the actual situation. To simulate the heat input of the pressure vessel nozzle, five plate

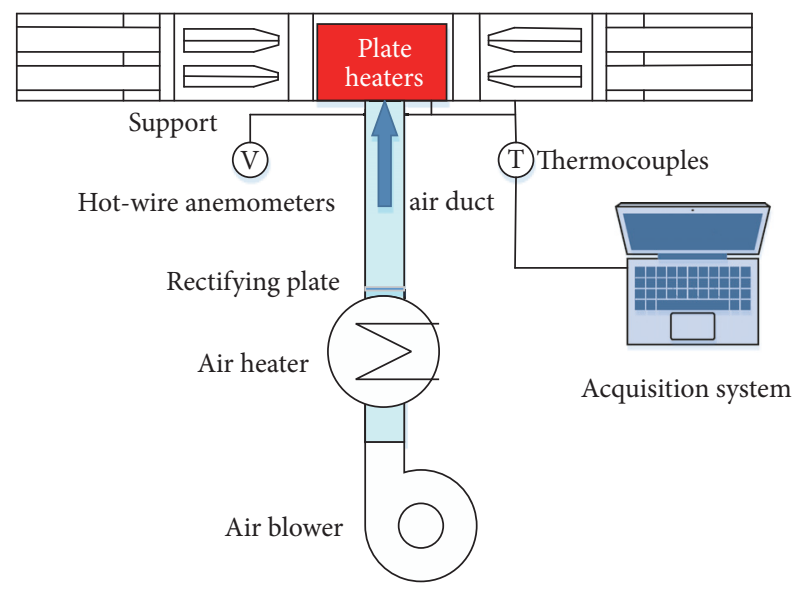

FIGURE 4: The schematic diagram of experimental facility.

heaters with total power up to $120 \mathrm{KW}$ are installed on the contact part of the support and nozzle (Figure 3). By adjusting the heating device power, the temperature is consistent with actual situation $\left(\sim 287^{\circ} \mathrm{C}\right)$. The entire support is exposed to the ambient environment.

Figure 4 shows the schematic diagram of experimental facility. It is composed of a support entity, five plate heaters, an air heater, and an air blower. The support temperature distribution is obtained under different conditions by adjusting inlet air velocity and temperature. The air heater is used to heat cool air coming from the air blower meeting experiment condition. The inlet air velocity can be adjusted by air blower. In order to ensure the uniformity of the inlet cooling air, an air duct up to 6 meters is built and a rectifying plate is added at the air heater outlet. On the section near the cooling air inlet of support, the air velocity and temperature are measured at different locations along the horizontal. Figure 4 shows schematic diagram of the experimental facility. It is composed of a support entity, five plate heaters, an air heater, and an air blower. The support temperature distribution is obtained under different conditions by adjusting inlet air velocity and temperature. The air heater is used to heat cool air coming from the air blower meeting experiment condition. The inlet air velocity can be adjusted by air blower. In order to ensure the uniformity of the inlet cooling air, an air duct up to 6 meters is built and a rectifying plate is added at the air heater outlet. On the section near the support cooling air inlet, the air velocity and temperature are measured at different locations along the horizontal centerline and vertical centerline, respectively.

The measurement parameters include the temperature of support side and bottom, the heating area, the inlet cooling air temperature, and the inlet air velocity. The temperature is measured by K-type sheathed thermocouples (measurement error is $\pm 1.5^{\circ} \mathrm{C}$ ) and NI PXIe-4353 acquisition system (acquisition accuracy is $\pm 0.3^{\circ} \mathrm{C}$ ). The air velocity is measured by OMEGA TVS-1100 hot-wire anemometer (measurement error is $\pm 2 \%$ ). 


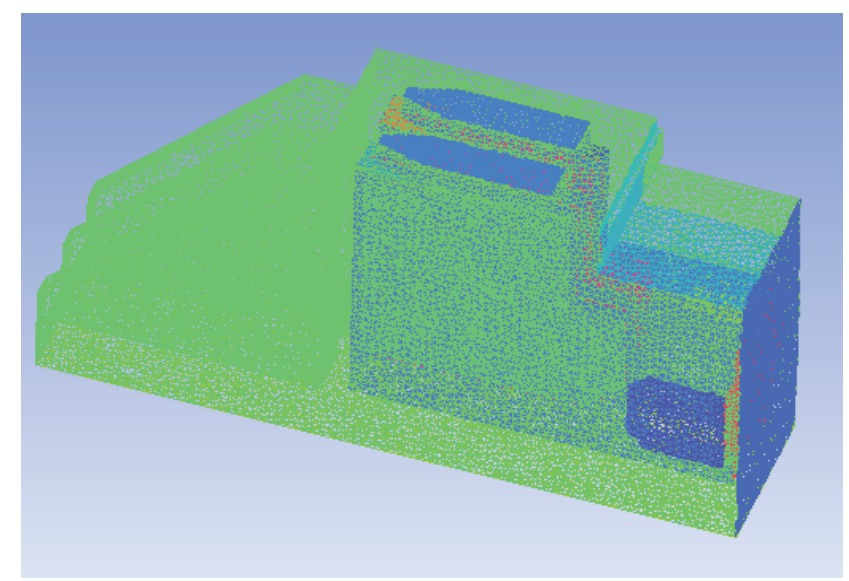

Figure 5: Meshing of the support.

TABLE 2: The physical property parameter of support and air.

\begin{tabular}{lcccccc}
\hline Physical property parameter & \multicolumn{3}{c}{ Support } & & Air \\
\hline Temperature $\left({ }^{\circ} \mathrm{C}\right)$ & 20 & 100 & 200 & 300 & 10 & 30 \\
Density $\left(\mathrm{kg} / \mathrm{m}^{3}\right)$ & 7570 & $/$ & $/$ & $/$ & 1.247 & 1.165 \\
Specific heat capacity $(\mathrm{J} /(\mathrm{kg} \cdot \mathrm{K}))$ & 470 & $/$ & $/$ & $/$ & 1005 & 1005 \\
Thermal conductivity $(\mathrm{W} /(\mathrm{m} \cdot \mathrm{K}))$ & 39.2 & 32.4 & 35.8 & 37.2 & 2.51 & 1.093 \\
Dynamic viscosity $(\mathrm{Pa} \cdot \mathrm{s})$ & $/$ & $/$ & $/$ & $/$ & 17.6 & 1005 \\
\hline
\end{tabular}

TABLE 3: The boundary conditions of calculation model.

\begin{tabular}{lc}
\hline Boundary conditions & Values \\
\hline Air inlet & Velocity-Inlet (Velocity 3-9 m/s, temperature 25-40 ${ }^{\circ} \mathrm{C}$ ) \\
Air outlet & Pressure-Outlet \\
Heating area & Fixed temperature $287^{\circ} \mathrm{C}$ \\
Support symmetry surface & Symmetrical \\
Support outside surface & Heat convection (Natural convection in an infinite space [23]) \\
\hline
\end{tabular}

\section{Numerical Simulation of RPV Support Temperature Distribution}

In order to obtain the temperature distribution and internal air flow field of the support, a finite volume method based on the CFD code Fluent 15.0 is adopted. The support is geometrically symmetrical, so only the left half part is simulated. The support material is cast iron and internal air is similar to dry air model. The geometric parameters and size are the same as support entity. The computational domain has been discretized using unstructured grids as shown in Figure 5. The grid elements are refined at the near-wall regions, air inlet and outlet. The grids have been chosen from the grid independent test.

The corresponding physical property parameter and boundary conditions are shown in Tables 2 and 3, respectively. The air inlet domain is considered as velocity-inlet. The constant flow velocity and temperature are the same as specific experimental conditions. Connecting to the atmosphere, the air outlet is set as pressure-outlet. The heating area is fixed as $287^{\circ} \mathrm{C}$. The contact area of support and internal cooling air is regarded as "Coupled" to simulate the heat exchange between them. All the walls are no-slip for the velocity. The symmetrical surface is set to symmetry. All the outside surfaces exchange heat with ambient surroundings by natural convection. The ambient temperature is consistent with actual experimental temperature. According to literature [23], the average natural convective heat transfer coefficient $h$ in an infinite space is calculated by

$$
\begin{aligned}
N u & =C(G r \operatorname{Pr})^{n} \\
G r & =\frac{g \alpha_{V} \Delta t l^{3}}{v^{2}} \\
h & =N u \frac{\lambda}{l}
\end{aligned}
$$

where $N u, G r, \operatorname{Pr}, g, v, \lambda$, and $l$ are the Nusselt number, Grashof number, Prandtl number, gravity acceleration, kinematic viscosity, heat conductivity coefficient of air, and characteristic length. Constant $\mathrm{C}$ and coefficient $\mathrm{n}$ are selected according to literature [24], $C=0.0292, n=0.39 . \alpha_{V}$ is the expansion coefficient. For ideal gas $\alpha_{V}=1 / T, T$ is the Kelvin's 


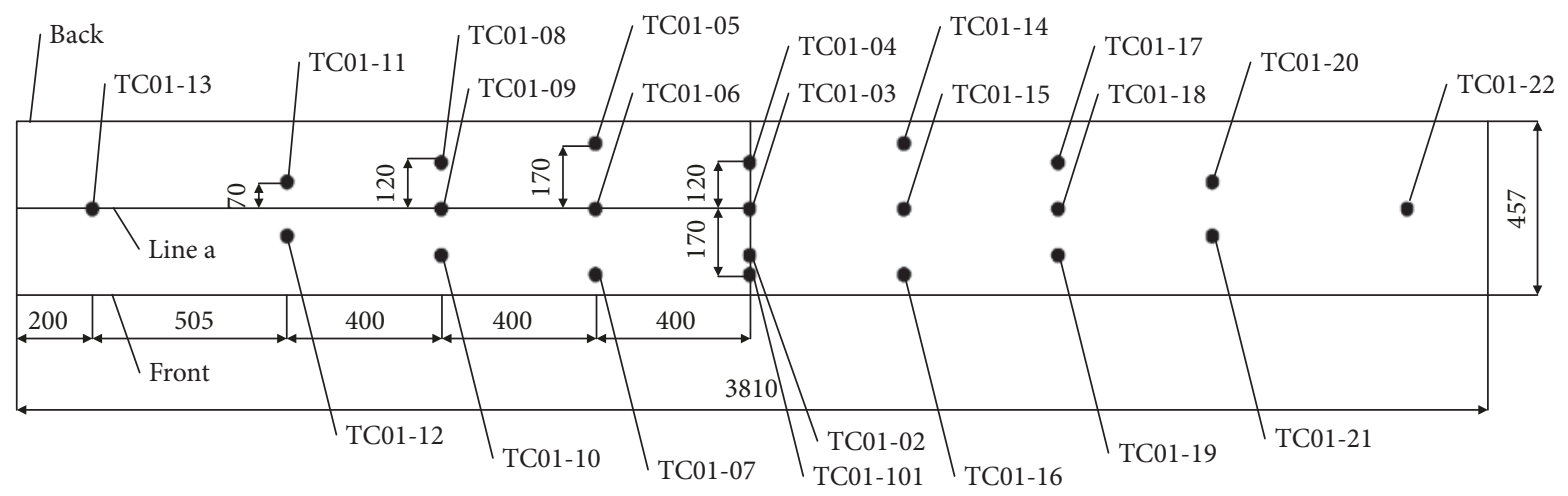

Figure 6: The temperature measurement positions of support bottom plate.

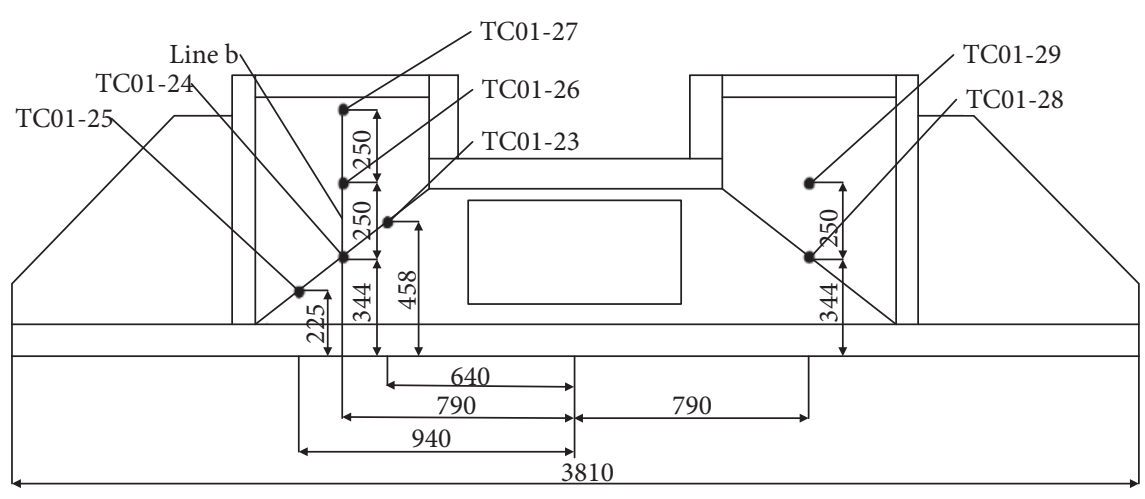

FIGURE 7: The temperature measuring positions of support front plat.

temperature of gas. $\Delta t=t_{w}-t_{\infty}$, where $t_{w}$ and $t_{\infty}$ are the wall temperature and ambient temperature.

The heat transfer and flow are steady. The solver type is pressure-based. The turbulent energy and turbulent dissipation rate are solved by standard $k-\varepsilon$ turbulent model. The pressure-velocity coupling is performed with the SemiImplicit Method for Pressure Linked Equations (SIMPLE) algorithm. The momentum and energy conservation equations are discretized with the second-order upwind scheme. The convergence criteria for stopping the solution are chosen to be $10^{-3}$.

\section{Results and Discussion}

4.1. The Results of Experiment and Numerical Simulation. The goal of this paper is to obtain the temperature distribution of designed support, as well as the effects of inlet cooling air temperature and velocity on it, so as to verify the rationality of the support design and to provide guidance for selecting the appropriate inlet cooling air parameters. A total of eight tests are done. The specific conditions are shown in Table 4. The support heating area temperature is controlled at $287^{\circ} \mathrm{C}$ $\left( \pm 3^{\circ} \mathrm{C}\right)$ in all tests. The temperature measurement positions of support bottom and front plate are shown in Figures 6 and
TABLE 4: The specific conditions for tests.

\begin{tabular}{lcc}
\hline Test number & Inlet air temperature $\left({ }^{\circ} \mathrm{C}\right)$ & inlet air velocity $(\mathrm{m} / \mathrm{s})$ \\
\hline B1 & 35.35 & 6.25 \\
TS1 & 25 & 6.25 \\
TS2 & 30 & 6.25 \\
TS3 & 40 & 6.25 \\
FS1 & 35.35 & 3 \\
FS2 & 35.35 & 5 \\
FS3 & 35.35 & 7 \\
FS4 & 35.35 & 9 \\
\hline
\end{tabular}

7. The numerical simulation values correspond to Line a and Line $b$.

Test B1 is similar to actual reactor situation. For numerical simulation, the velocity field distribution is shown in Figure 8 . The outlet air velocity close to the back plate is larger than inlet air velocity, whereas the outlet air velocity near the front plate is opposite. Because the cooling air turns sharply after hitting the back plate, the flow direction changing from horizontal to vertical. Most of the cooling air flows through the channel near back plate. In addition, the velocity gradually increases along the normal direction of 


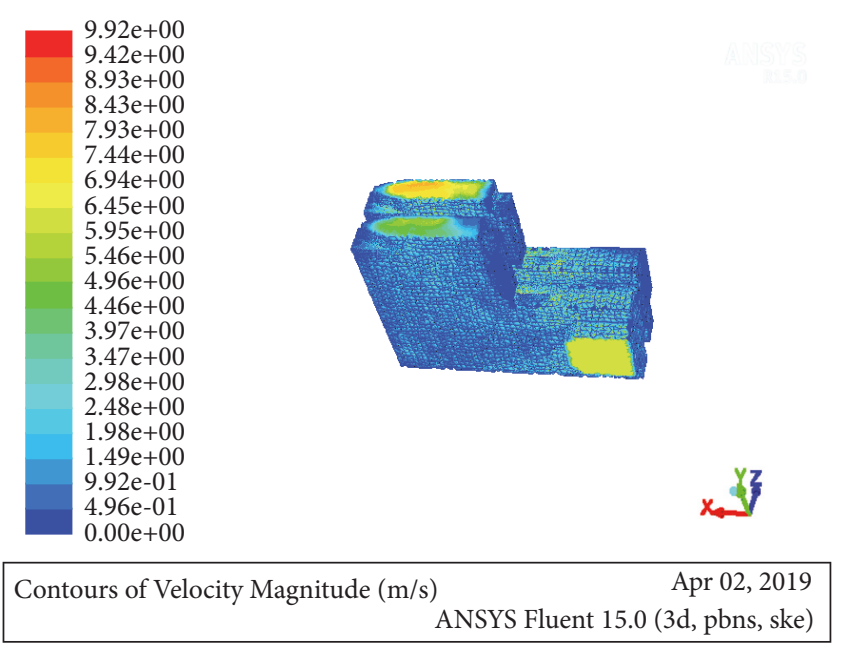

FIGURE 8: The velocity distribution of support in Test B1.



FIGURE 9: The temperature distribution of support in Test B1.

the air-support contact surface, and the maximum velocity appears near the centerline of the channel. This is consistent with classical hydrodynamics pipe turbulent flow [25]. The maximum air velocity is $9.92 \mathrm{~m} / \mathrm{s}$; the minimum is $0.02 \mathrm{~m} / \mathrm{s}$. Air velocity distribution inside the support is very uneven. So the long-term impact of internal air on the support should be considered when selecting inlet air velocity under actual reactor operation.

The support temperature distribution and the bottom temperature distribution are shown in Figures 9 and 10, respectively. As can be seen from Figure 9, during the actual operation, the temperature distribution of support is very uneven. The temperature decreases gradually from the area contacting with nozzle to the surface and bottom. The highest temperature is $287^{\circ} \mathrm{C}$ and the lowest is $14.9^{\circ} \mathrm{C}$. Therefore, the thermal stress caused by uneven temperature field should be considered in the design of support. The temperature near the front plate is slightly higher than that near the back plate which is consistent with cooling air velocity because larger air velocity can take away more heat. For the support bottom

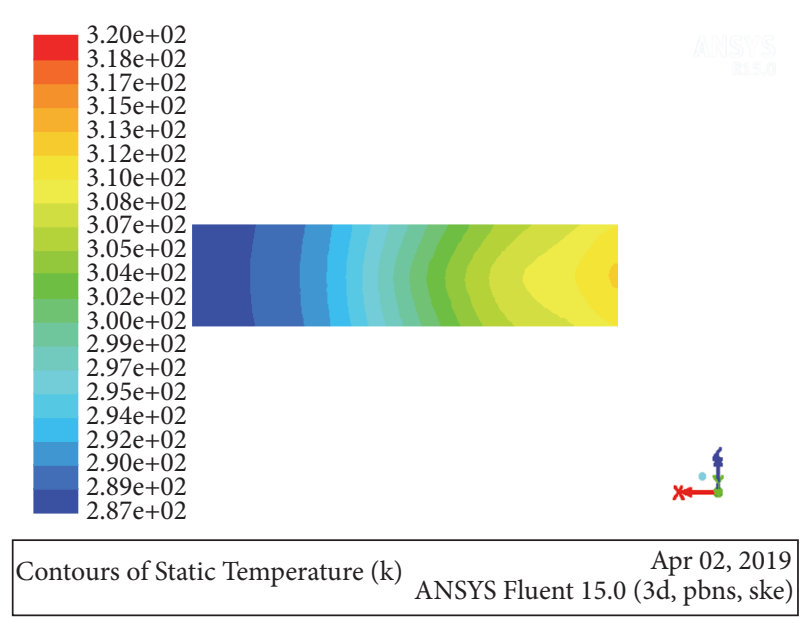

FIgURE 10: The temperature distribution of support bottom in Test B1.

as shown in Figure 10, the highest temperature appears in center and gradually decreases to both sides. The maximum temperature of the bottom is $38.8^{\circ} \mathrm{C}$; the minimum is $14.9^{\circ} \mathrm{C}$.

For the experiment, the temperature distribution of support bottom is shown in Figure 11. It distributes symmetrically along the longitudinal center line. The closer it is to the center, the higher the temperature is, because the center is located just below the heating area. The maximum temperature is about $38^{\circ} \mathrm{C}$, much less than the bottom temperature limit of $93^{\circ} \mathrm{C}$, indicating that the modified support meets the safety requirements of nuclear power plants considering from the view of thermodynamics. The minimum temperature of support bottom is about $17^{\circ} \mathrm{C}$, appearing in the area below the support rib plate, which is farthest from the heating area.

The most typical temperature contrasts of simulation and experiment at the support bottom and front are shown in Figures 12 and 13, respectively. All values are listed in Table 5. The results of simulation are consistent with the experiment, with the error less than $\pm 4^{\circ} \mathrm{C}$.

4.2. Effects of Inlet Cooling Air Temperature and Velocity on Support Temperature Distribution. The temperature and velocity of inlet cooling air will affect the cooling on support. In order to meet the support bottom temperature limit in reactor, it is necessary to get the most appropriate inlet cooling air temperature and velocity. Figures 14 and 15 show the temperature distribution of experiments at the support bottom and front, respectively, under Test B1, TSI, TS2, and TS3 conditions (corresponding to inlet cooling air temperatures of $35.35^{\circ} \mathrm{C}, 25^{\circ} \mathrm{C}, 30^{\circ} \mathrm{C}$, and $40^{\circ} \mathrm{C}$, respectively). The bottom temperature gradually increases with the increase of inlet cooling air temperature. Inlet cooling air temperature has a greater effect on the bottom near the center than both sides. Maintaining velocity at $6.25 \mathrm{~m} / \mathrm{s}$, as inlet cooling air temperature increases from $25^{\circ} \mathrm{C}$ to $40^{\circ} \mathrm{C}$, the maximum temperature of support bottom (the center) increases about $11.49^{\circ} \mathrm{C}$ (from $29.03^{\circ} \mathrm{C}$ to $40.52^{\circ} \mathrm{C}$ ). But as the temperature increases, its influence on the bottom temperature is rapidly 


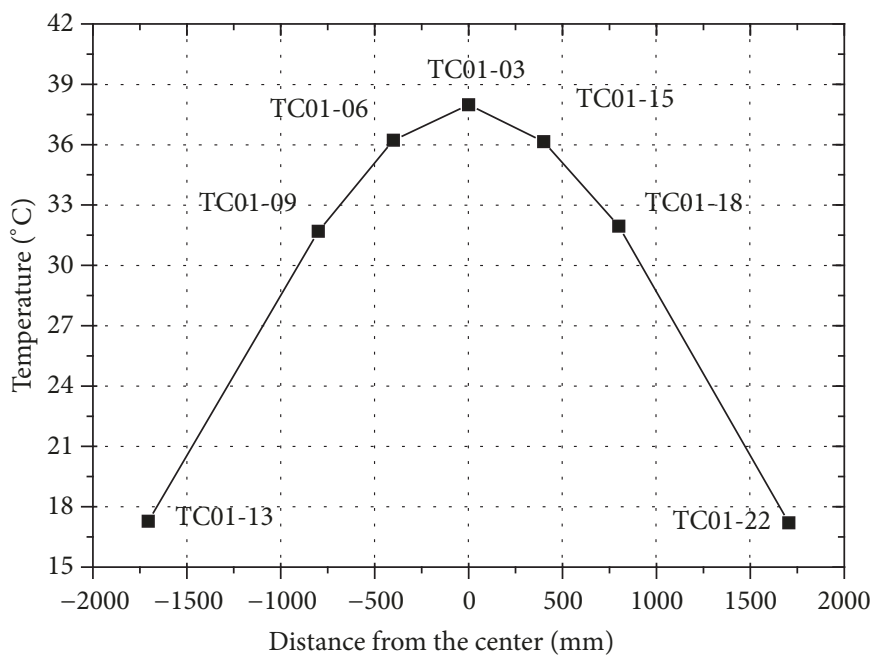

FIGURE 11: The experimental temperature distribution of support bottom in Test B1.



FIGURE 12: The temperature contrast of simulation and experiment at the support bottom in Test B1.

reduced (from $25^{\circ} \mathrm{C}$ to $30^{\circ} \mathrm{C}$, the maximum temperature increasing $6.79^{\circ} \mathrm{C}$, while from $30^{\circ} \mathrm{C}$ to $40^{\circ} \mathrm{C}$, only increasing $\left.4.74^{\circ} \mathrm{C}\right)$

As can be seen from Figure 15, the temperature of support front plate gradually decreases from top to bottom and increases with the increase of the inlet air temperature. The effect of inlet air temperature on front plate is similar to the bottom plate.

The velocity distribution and bottom temperature distribution of numerical simulation under different inlet cooling air temperature (taking Test TS1 as an example) are shown in Figures 16 and 17. The contrasts of numerical simulation temperature distribution at bottom and front plate between Test B1 and TS1 are shown in Figures 18 and 19. Comparing Figures 8 and 16, there are very small differences in the air velocity distribution inside the support, indicating that the inlet air temperature does not significantly affect the air velocity. Inlet air temperature has a great effect on the bottom temperature. As the inlet air temperature increases from $25^{\circ} \mathrm{C}$ to $35.35^{\circ} \mathrm{C}$, the numerical simulation maximum temperature of bottom (the center) increases about $7.89^{\circ} \mathrm{C}$ (from $30.88^{\circ} \mathrm{C}$ to $38.77^{\circ} \mathrm{C}$ ), which is closely to the experimental result of increasing about $8.99^{\circ} \mathrm{C}$ (from $28.99^{\circ} \mathrm{C}$ to $37.98^{\circ} \mathrm{C}$ ).

The temperature contrasts of simulation and experiment at the bottom plate and front in Test TS1 are shown in Figures 20 and 21. The results of temperature simulation are consistent with the experimental results, with the error less than $\pm 4^{\circ} \mathrm{C}$, which ensures the reliability of the experiment and numerical simulation.

Figures 22 and 23 show the inlet cooling air velocity effect on temperature distribution of bottom and front plate, respectively, under experimental conditions of Test FS1, FS2, FS3, and FS4 (corresponding to inlet cooling air velocity of $3 \mathrm{~m} / \mathrm{s}, 5 \mathrm{~m} / \mathrm{s}, 7 \mathrm{~m} / \mathrm{s}$, and $9 \mathrm{~m} / \mathrm{s}$, respectively). At the center 


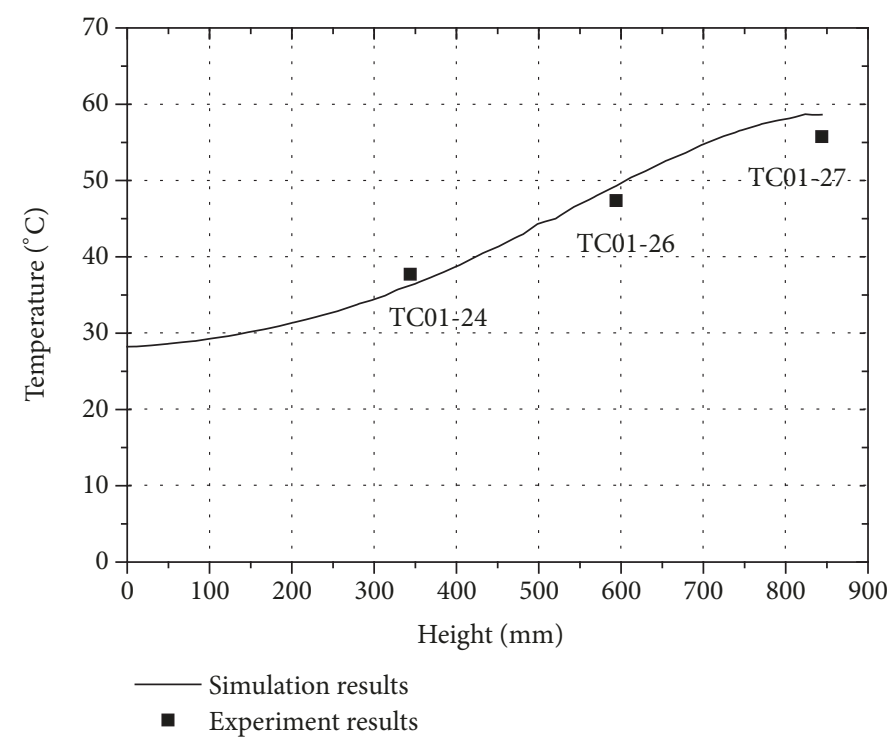

FIGURE 13: The temperature contrast of simulation and experiment at the support front plate in Test B1.

TABLE 5: The temperature contrast of experiment and simulation at the support bottom and front.

\begin{tabular}{lcc}
\hline Measuring position & Experiment $\left({ }^{\circ} \mathrm{C}\right)$ & Numerical simulation $\left({ }^{\circ} \mathrm{C}\right)$ \\
\hline TC01-01 & 37.16 & 37.65 \\
TC01-02 & 37.65 & 38.15 \\
TC01-03 & 37.98 & 38.77 \\
TC01-04 & 37.99 & 38.08 \\
TC01-05 & 35.95 & 34.1 \\
TC01-06 & 36.22 & 35.5 \\
TC01-07 & 35.91 & 34.69 \\
TC01-08 & 31.60 & 28.94 \\
TC01-09 & 31.69 & 32.07 \\
TC01-10 & 31.69 & 29.38 \\
TC01-11 & 23.82 & 20.69 \\
TC01-12 & 24.19 & 20.77 \\
TC01-13 & 17.28 & 15.26 \\
TC01-14 & 36.06 & 34.10 \\
TC01-15 & 36.15 & 35.50 \\
TC01-16 & 35.73 & 34.69 \\
TC01-18 & 31.95 & 32.07 \\
TC01-19 & 31.99 & 29.38 \\
TC01-20 & 24.47 & 20.69 \\
TC01-21 & 24.61 & 20.77 \\
TC01-22 & 17.20 & 15.26 \\
TC01-23 & 49.35 & 55.73 \\
TC01-24 & 37.71 & 49.43 \\
TC01-25 & 37.24 \\
TC01-26 & 47.38 .37 \\
TC01-27 & \\
TC01-28 & TC01-29 & \\
\hline
\end{tabular}

of bottom plate, the temperature decreases obviously with the inlet air velocity increasing, but the inlet air has little effect on the temperature of two sides. And as the air velocity increases, its influence on the center temperature gradually decreases. Maintaining inlet air temperature at $35.35^{\circ} \mathrm{C}$, as inlet air velocity increases from $3 \mathrm{~m} / \mathrm{s}$ to $5 \mathrm{~m} / \mathrm{s}$, the maximum temperature of support bottom (the center) decreases about $3.07^{\circ} \mathrm{C}$ (from $41.56^{\circ} \mathrm{C}$ to $38.49^{\circ} \mathrm{C}$ ). When velocity increases from $5 \mathrm{~m} / \mathrm{s}$ to $7 \mathrm{~m} / \mathrm{s}$, the maximum temperature decreases only about $1.34^{\circ} \mathrm{C}$, and the temperature almost no longer decreases when the inlet air velocity is greater than $7 \mathrm{~m} / \mathrm{s}$. Figure 23 shows that the front plate temperature decreases as the inlet cooling air velocity increases. The effects of inlet air velocity on front plate are similar to the bottom plate.

The velocity distribution and bottom temperature distribution of numerical simulation results under different inlet cooling air velocity (taking Test FS1 as an example) are shown in Figures 24 and 25. The temperature contrasts of bottom and front plate between Test B1 and TS1 are shown in Figures 26 and 27. Comparing Figures 9 and 24, the air velocity inside the support is significantly reduced (the maximum velocity is $9.92 \mathrm{~m} / \mathrm{s}$ and $4.61 \mathrm{~m} / \mathrm{s}$, respectively). Inlet air velocity has a greater effect on the bottom plate near the center than both sides. As the inlet air velocity increases from $3 \mathrm{~m} / \mathrm{s}$ to $6.25 \mathrm{~m} / \mathrm{s}$, the numerical simulation maximum temperature of support bottom (the center) decreases about $4.37^{\circ} \mathrm{C}$ (from $43.14^{\circ} \mathrm{C}$ to $38.77^{\circ} \mathrm{C}$ ), which is closely to the experimental result of decreasing about $3.58^{\circ} \mathrm{C}$ (from $41.56^{\circ} \mathrm{C}$ to $37.98^{\circ} \mathrm{C}$ ).

The temperature contrasts of simulation and experiment at the bottom plate and front in Test FS1 are shown in Figures 28 and 29. The results of temperature simulation are consistent with the experimental results, with the error less than $\pm 4^{\circ} \mathrm{C}$, which ensures the reliability of the experiment and numerical simulation.

From the above, under the actual support inlet air temperature $\left(35.35^{\circ} \mathrm{C}\right)$ and velocity $(6.25 \mathrm{~m} / \mathrm{s})$ in reactor, the 


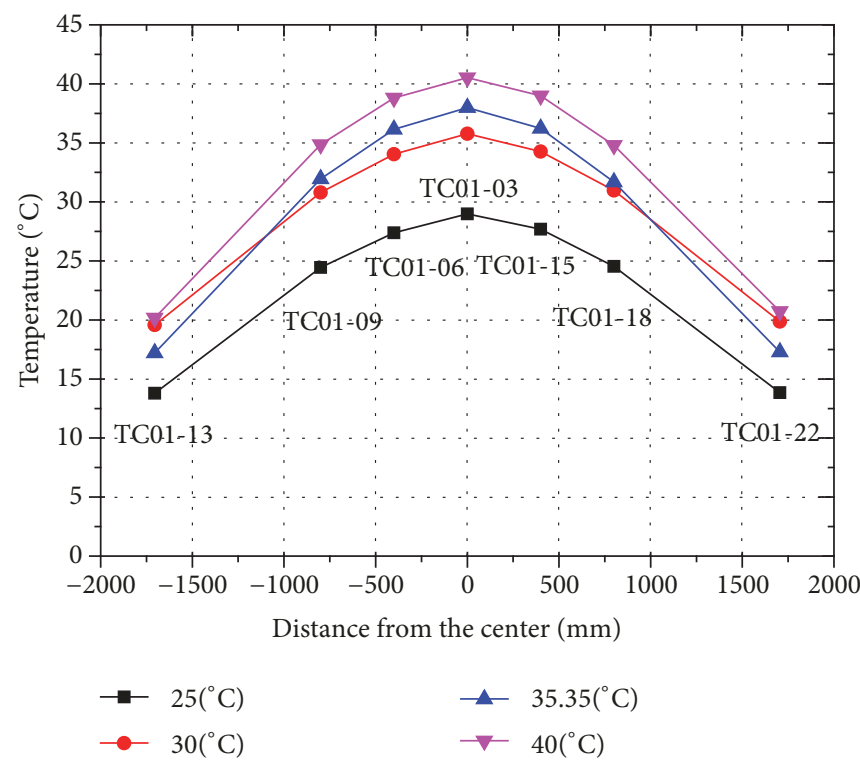

FIGURE 14: The effect of inlet cooling air temperature on support bottom.

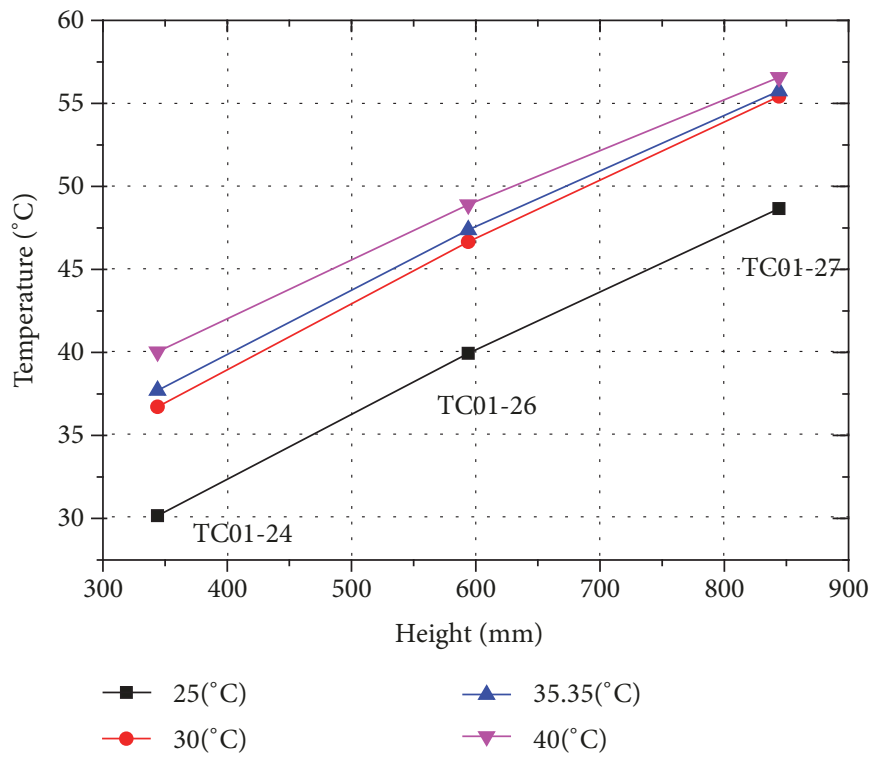

Figure 15: The effect of inlet cooling air temperature on support front plate.

maximum temperature of designed support bottom is about $38^{\circ} \mathrm{C}$, which meets the contacting concrete limit requirement (not exceeding $93.3^{\circ} \mathrm{C}$ ). Even considering more conservative conditions (such as higher air temperature or lower air velocity), the design still meets the requirement. In addition, it can be seen from the results that the inlet air temperature has a greater effect on the support bottom temperature than the velocity, so in order to reduce support bottom temperature and at the same time reduce the impacts of air on support, a better approach is to lower the inlet air temperature (for example, reduce the heat absorbed from the thermal insulation layer), rather than increasing its velocity by improving the air blower capacity.
4.3. The Temperature Distribution of Support under Adiabatic Boundary Condition. In the experiment, the entire surface of support is directly in contact with the atmospheric environment, and the ambient temperature is about $10^{\circ} \mathrm{C}$. Under the actual operation of the reactor, the bottom of the support is in contact with the concrete, and the side of the support is exposed to the surrounding environment where the temperature may be higher than the experiment. Therefore, considering from a conservative perspective, in order to ensure that the support meets the design requirements during actual operation, it is necessary to use the validated numerical model to calculate the temperature distribution of the support under 




FIgURE 16: The velocity distribution of support in Test TS1.



FIGURE 17: The bottom temperature distribution of support in Test TS1.

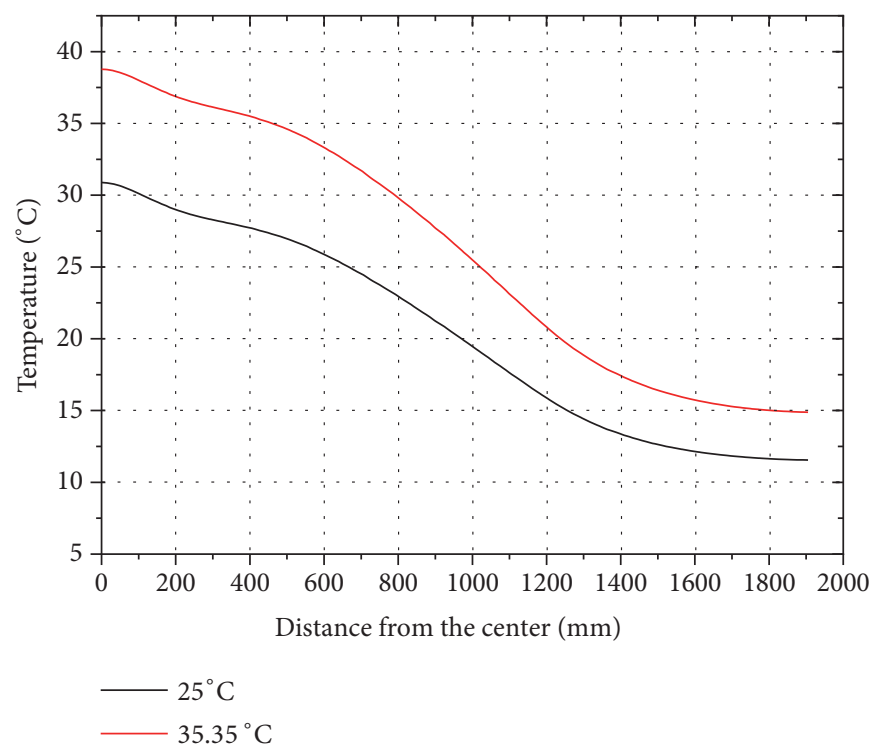

FIGURE 18: The temperature contrast of support bottom between Test B1 and TS1. 


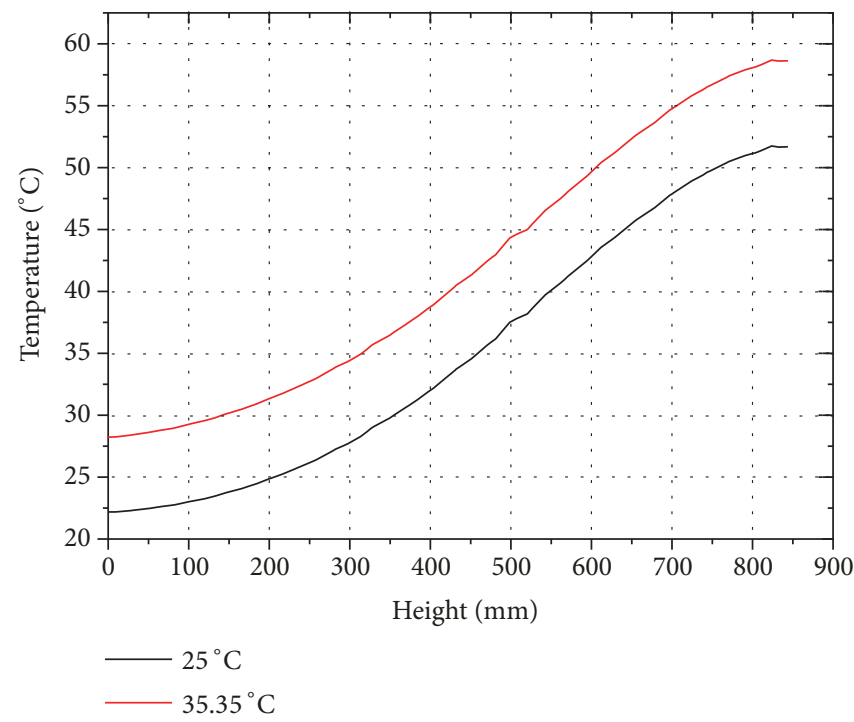

FIgURE 19: The temperature contrast of front plate between Test B1 and TS1.

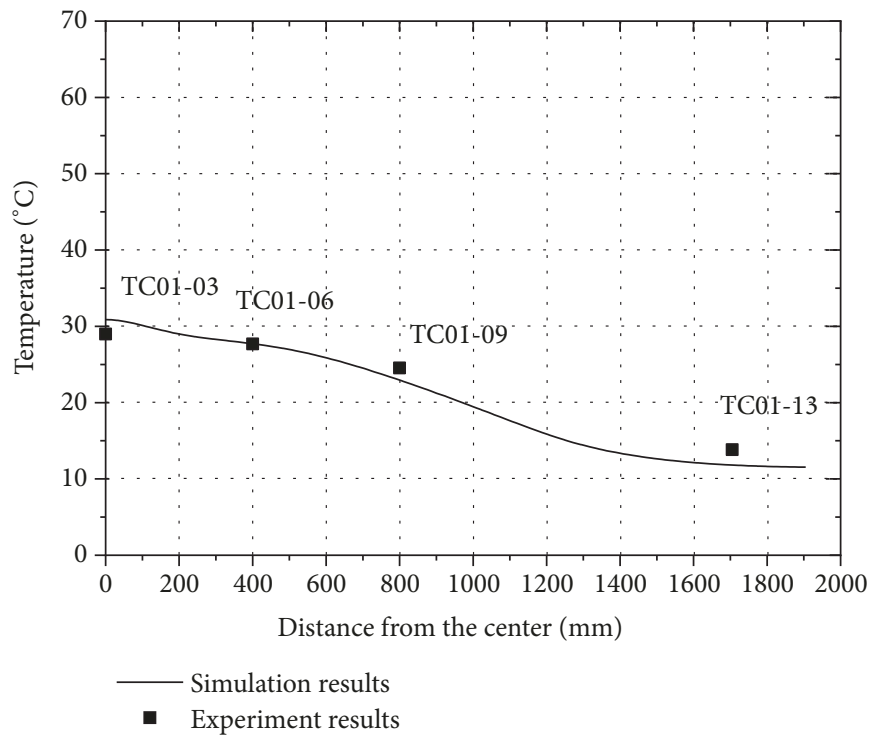

FIGURE 20: The temperature contrast of simulation and experiment at the bottom plate in Test TS1.

adiabatic condition to see if the design requirements are met.

Figures 30 and 31 show the temperature distribution of the support bottom under the conditions that the surface is adiabatic and the inlet air is consistent with the actual reactor operating conditions (temperature $35.35^{\circ} \mathrm{C}$ and velocity 6.25 $\mathrm{m} / \mathrm{s}$ ). From the center to side, the temperature of the bottom decreases first and then increases. The turning point just appears at the end of air channel. The decrease is because it is farther and farther away from the heating area at the top of the support, and the increase is because it cannot be directly cooled by the inlet cooling air after the end of the air channel. Figure 32 is the front plate temperature distribution of support under adiabatic boundary condition. The trend is similar to Test B1, but the temperature is much higher.
Under the most conservative condition (external surface insulation), the maximum temperature of the support bottom is $63.52^{\circ} \mathrm{C}$, which is still much lower than the concrete temperature limit of $93^{\circ} \mathrm{C}$. It shows that the modified support structure still meets the design requirements.

\section{Conclusions}

This paper investigates the temperature distribution of modified RPV support by experimental and numerical simulation methods. In order to simulate the actual operating conditions in the reactor as much as possible, a support entity is manufactured in a ratio of 1:1. The temperature and velocity of the inlet cooling air are also consistent with the actual situation. The experimental and numerical simulation results 




FIGURE 21: The temperature contrast of simulation and experiment at the support front plate in Test TS1.

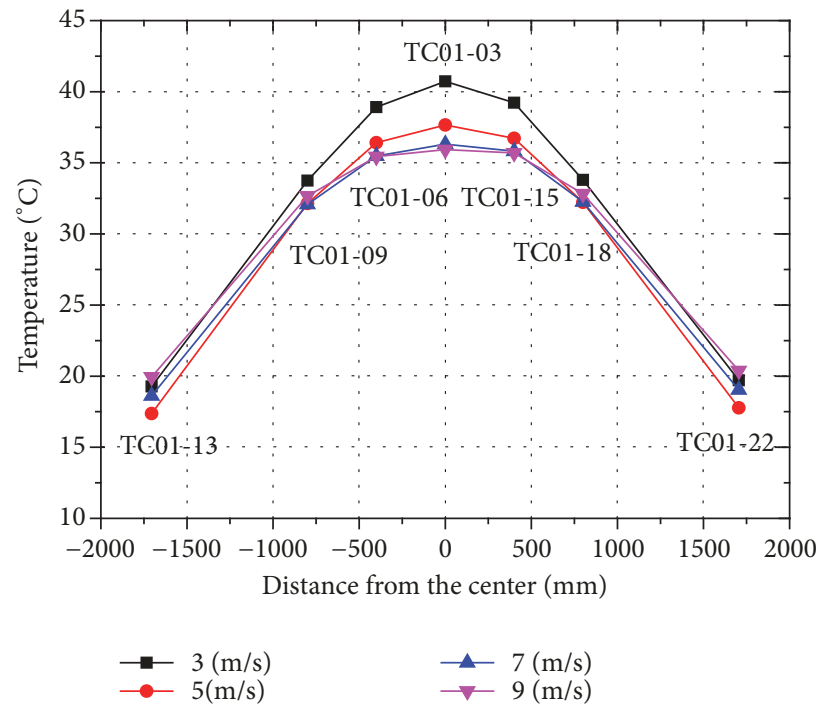

FIGURE 22: The effect of inlet cooling air velocity on support bottom plate.

agree well with the error less than $\pm 4^{\circ} \mathrm{C}$. The maximum temperature of designed support bottom is $38.8^{\circ} \mathrm{C}$, which is far less than the allowable temperature of shielded concrete contacting with the support bottom, indicating that the design can ensure the concrete not fail. So the modified RPV support is reliable.

The influence of inlet cooling air temperature and velocity on the maximum temperature of the support bottom is also studied. Lowering the inlet cooling air temperature and increasing the velocity can reduce the maximum temperature, but the effect of inlet cooling air temperature on the maximum temperature is more significant. In addition, excessive inlet air velocity may have a great impact on the support. So in order to improve the cooling capacity of the air, a better way is to reduce the inlet cooling air temperature in practice.
The temperature distribution of support under surface adiabatic condition is calculated with the validated model. The maximum temperature of support bottom is $63.52^{\circ} \mathrm{C}$. So even under the most conservative condition (external surface insulation), the maximum temperature of the support bottom is still much lower than the concrete temperature limit of $93^{\circ} \mathrm{C}$.

Overall, the paper has verified that the modified RPV support satisfies the design requirements under operating conditions.

\section{Data Availability}

The data used to support the findings of this study are available from the corresponding author upon request. 




FIGURE 23: The effect of inlet cooling air velocity on support front plate.

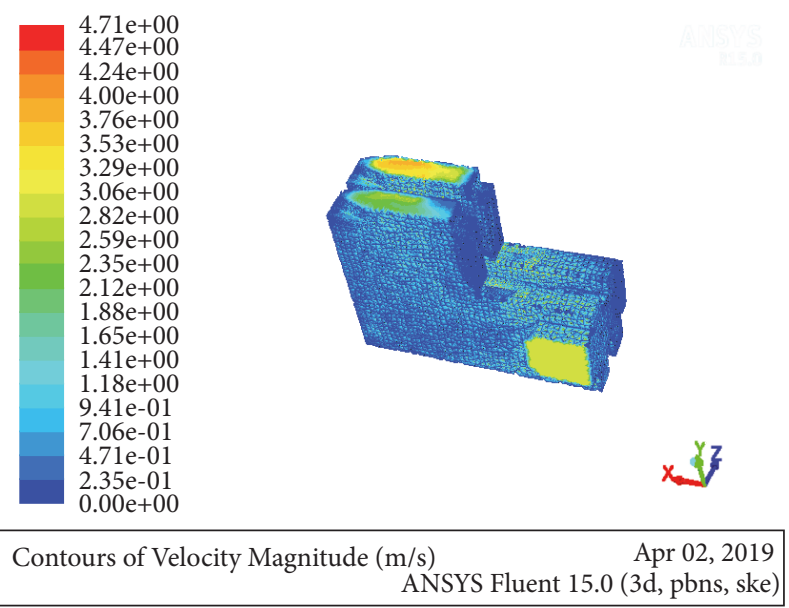

FIGURE 24: The velocity distribution of support in Test FS1.

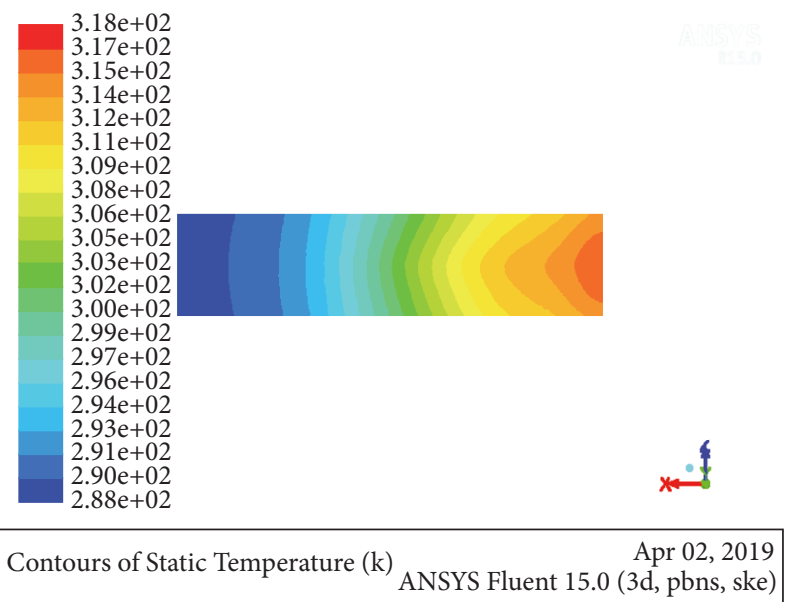

FIGURE 25: The bottom temperature distribution of support in Test FS1. 


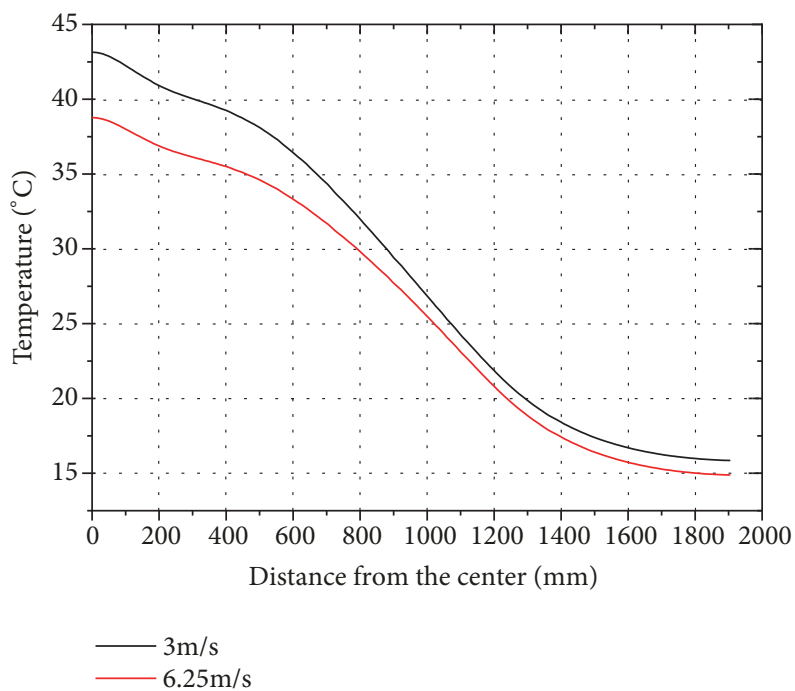

FIGURE 26: The temperature contrast of bottom plate between Test B1 and FS1.

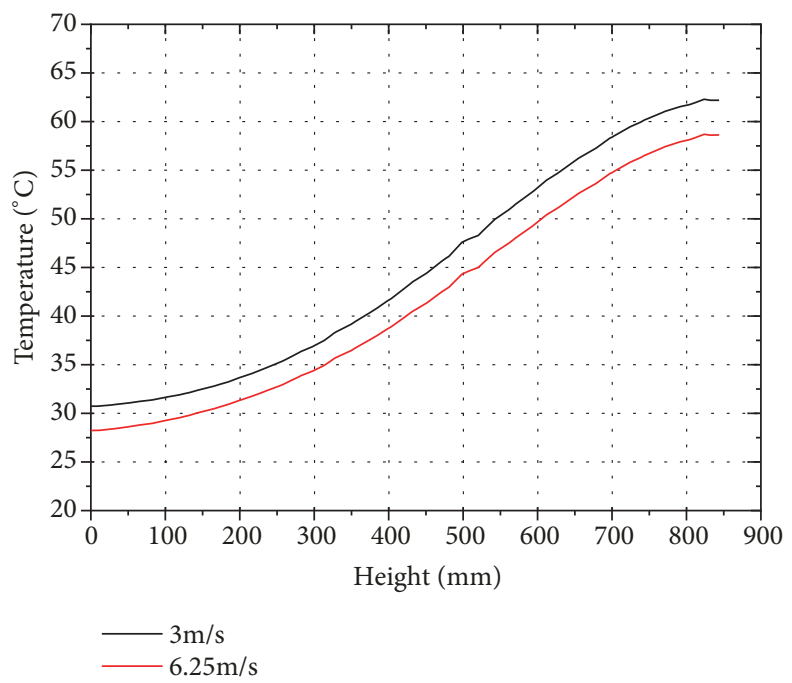

FIgURE 27: The temperature contrast of front plate between Test B1 and FS1.

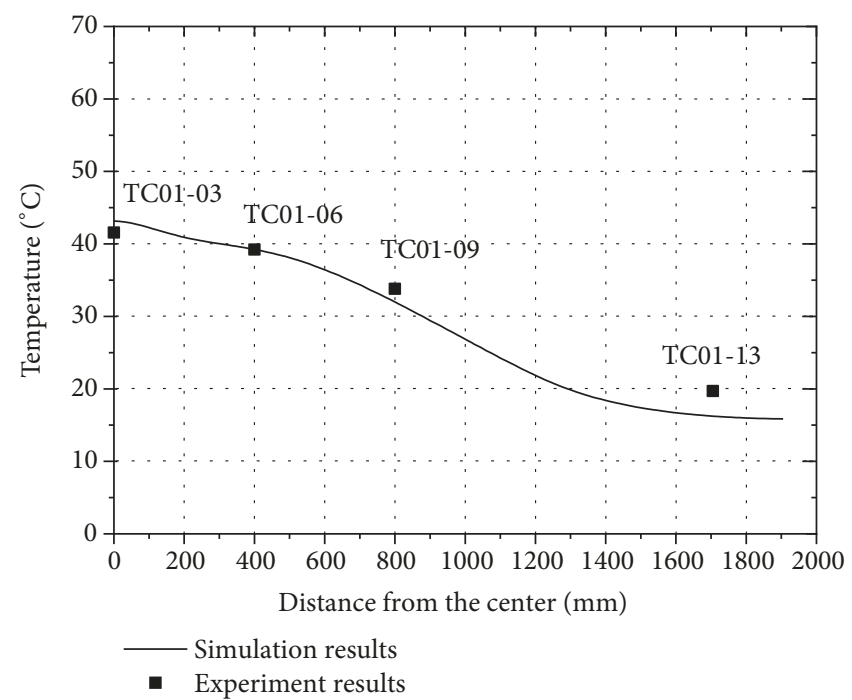

FIGURE 28: The temperature contrast of simulation and experiment at the support bottom plate in Test FS1. 


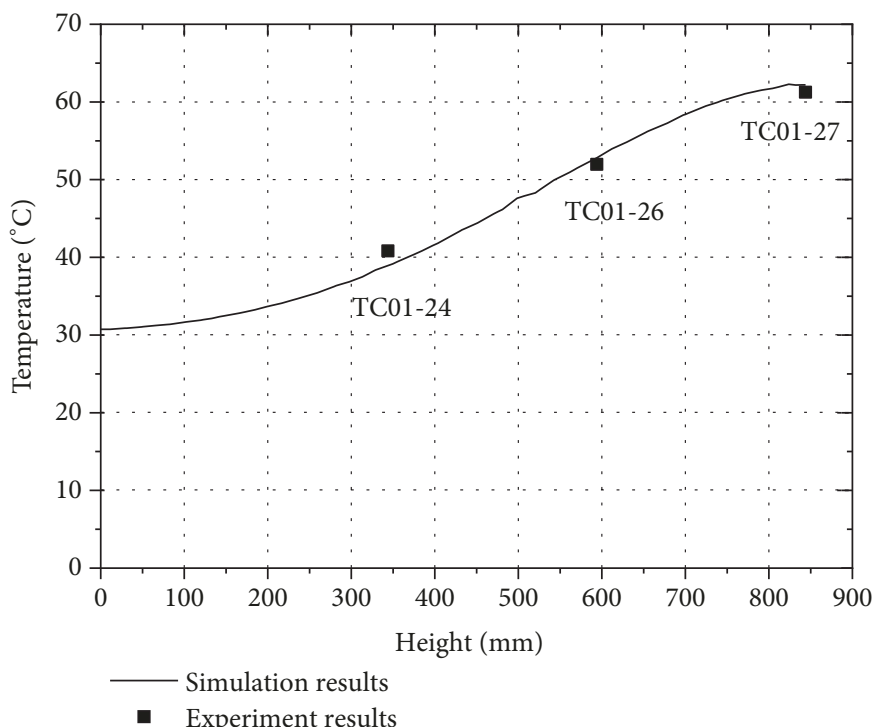

FIgURE 29: The temperature contrast of simulation and experiment at the support front plate in Test FS1.



FIGURE 30: The bottom temperature distribution of support under adiabatic boundary condition.

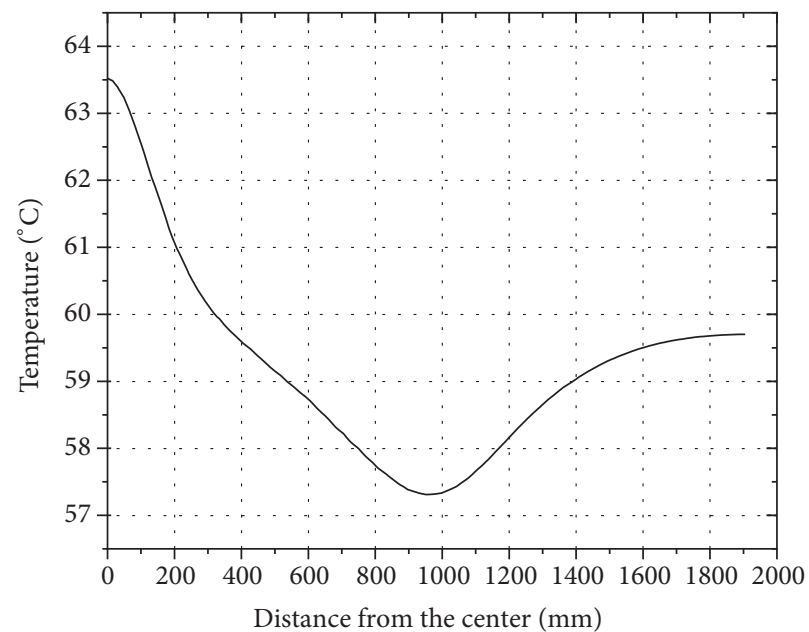

- Adiabatic boundary

FIGURE 31: Temperature distribution on the centerline of the support bottom under adiabatic boundary condition. 


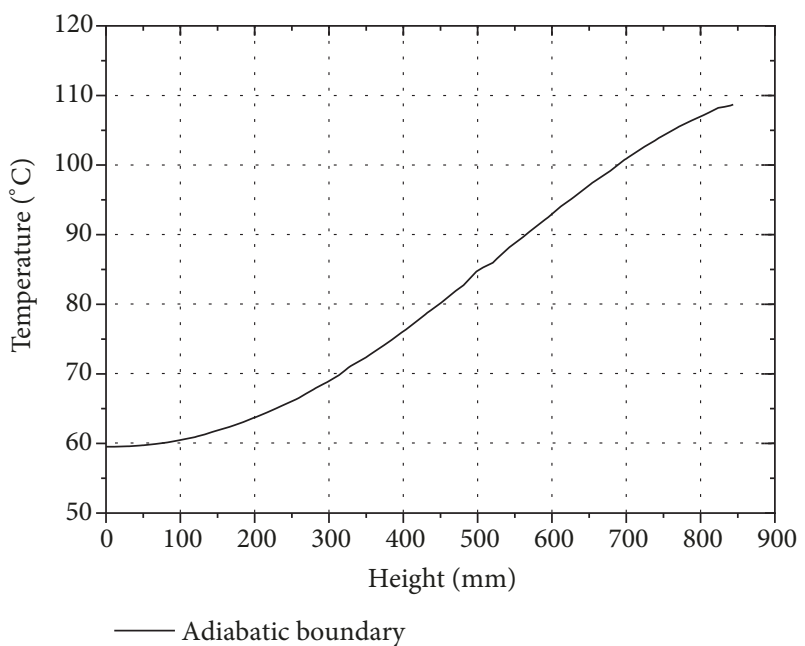

FIGURE 32: The front plate temperature distribution of support under adiabatic boundary condition.

\section{Conflicts of Interest}

The authors declare that they have no conflicts of interest.

\section{Acknowledgments}

The financial support received from the national science and technology major project "Pressure Vessel and Integrated Heap Top Component Design Technology Research (2011ZX06002-002-001)”.

\section{References}

[1] Westinghouse, AP1000 Design Control Document Rev. 19 Tier 2 (Chapter 5), 2011.

[2] S. Hanhong, The Third Generation Nuclear Power TechnologyAP1000, Chinese Electricity Power Press, Beijing, China, 2010.

[3] Code Requirements for Nuclear Safety-Related Concrete Structures and Commentary (ACI 349-13), 2013.

[4] ASME Boiler and Pressure Vessel Code, Section III Subsection NF Supports, 2015.

[5] Korea Hydro and Nuclear Power Co., APR1400 Design Control Document, Tier2 (Chapters 3), 2014.

[6] “EPR Design Description, AREVA, 2005”.

[7] "Design description of VVER-1000 (Khmelnytsky NPP)," http://bib.convdocs.org/v10951/?cc=1 .

[8] X. Guo, J. Cai, and Y. Wang, "Modal analysis of the helical tube in a small nuclear reactor's steam generator using a finite element method," Annals of Nuclear Energy, vol. 114, pp. 354358, 2018.

[9] D. De Santis and A. Shams, "Numerical modeling of flow induced vibration of nuclear fuel rods," Nuclear Engineering and Design, vol. 320, pp. 44-56, 2017.

[10] Y.-H. Heo and S.-H. Oh, "Design modification and shaking table test of the drain pipes of steam generator for vibration reduction," Nuclear Engineering and Design, vol. 340, pp. 68-72, 2018.

[11] X. Wang and Y. Lu, "Optimization of the cross section area on the meridian surface of the $1400-\mathrm{MW}$ canned nuclear coolant pump based on a new medial axial transform design method," Annals of Nuclear Energy, vol. 115, pp. 466-479, 2018.

[12] S. A. Ansari, M. Haroon, A. Rashid, and Z. Kazmi, "Measurement and analysis of structural integrity of reactor core support structure in pressurized water reactor (PWR) plant," IEEE Transactions on Nuclear Science, vol. 64, no. 2, pp. 844851, 2017.

[13] R. Dhayalan, A. Kumar, and B. P. Rao, "Numerical analysis of frequency optimization and effect of liquid sodium for ultrasonic high frequency guided wave inspection of core support structure of fast breeder reactor," Annals of Nuclear Energy, vol. 115, pp. 233-242, 2018.

[14] Q. Xu, J. Chen, C. Zhang, J. Li, and C. Zhao, "Dynamic analysis of AP1000 shield building considering fluid and structure interaction effects," Nuclear Engineering and Technology, vol. 48, no. 1, pp. 246-258, 2016.

[15] J.-B. Park, Y. Choi, S.-J. Lee et al., "Modal characteristic analysis of the APR1400 nuclear reactor internals for seismic analysis," Nuclear Engineering and Technology, vol. 46, no. 5, pp. 689-698, 2014.

[16] S. Y. Je, Y.-S. Chang, and S.-S. Kang, "Dynamic characteristics assessment of reactor vessel internals with fluid-structure interaction," Nuclear Engineering and Technology, vol. 49, no. 7, pp. 1513-1523, 2017.

[17] M. K. Kim, I.-K. Choi, and J.-M. Seo, "A shaking table test for an evaluation of seismic behavior of $480 \mathrm{v}$ MCC," Nuclear Engineering and Design, vol. 243, pp. 341-355, 2012.

[18] Y. Choi, S. Lim, B.-H. Ko et al., "Dynamic characteristics identification of reactor internals in SMART considering fluidstructure interaction," Nuclear Engineering and Design, vol. 255, pp. 202-211, 2013.

[19] A. T. Nguyen and I. Namgung, "Structural assessments of plate type support system for APR1400 reactor," Nuclear Engineering and Design, vol. 314, pp. 256-270, 2017.

[20] L. Jiaqi and L. Dongan, "Fluid-solid coupling analysis and optimal design for RPV support," Mechanical Engineer, vol. 5, pp. 87-90, 2013.

[21] L. Dongan and C. Yufan, "Analysis of coupling fluid-temperature-field for RPV," Mechanical Research \& Application, vol. 3, pp. 74-76, 2012.

[22] L. Dongan and C. Yufan, “"Fluid-structure” coupling analysis of RPV support," in Proceedings of the 17th National Conference on Structural Mechanics in Reactor Technology, 2012.

[23] Y. Shiming and T. Wenquan, Heat Transfer, Higher Education Press, Beijing, China, 4th edition, 2006.

[24] S. M. Yang and Z. Z. Zhang, "An experimental study of natural convection heat transfer from a horizontal cylinder in high Rayleigh number laminar and turbulent region," in Proceedings of the 10th International Heat Transfer Conference, G. F. Hewitt, Ed., vol. 7, pp. 185-189, Brighton, UK, 1994.

[25] D. Zurong, Fluid Mechanics, Higher Education Press, Beijing, China, 2003. 

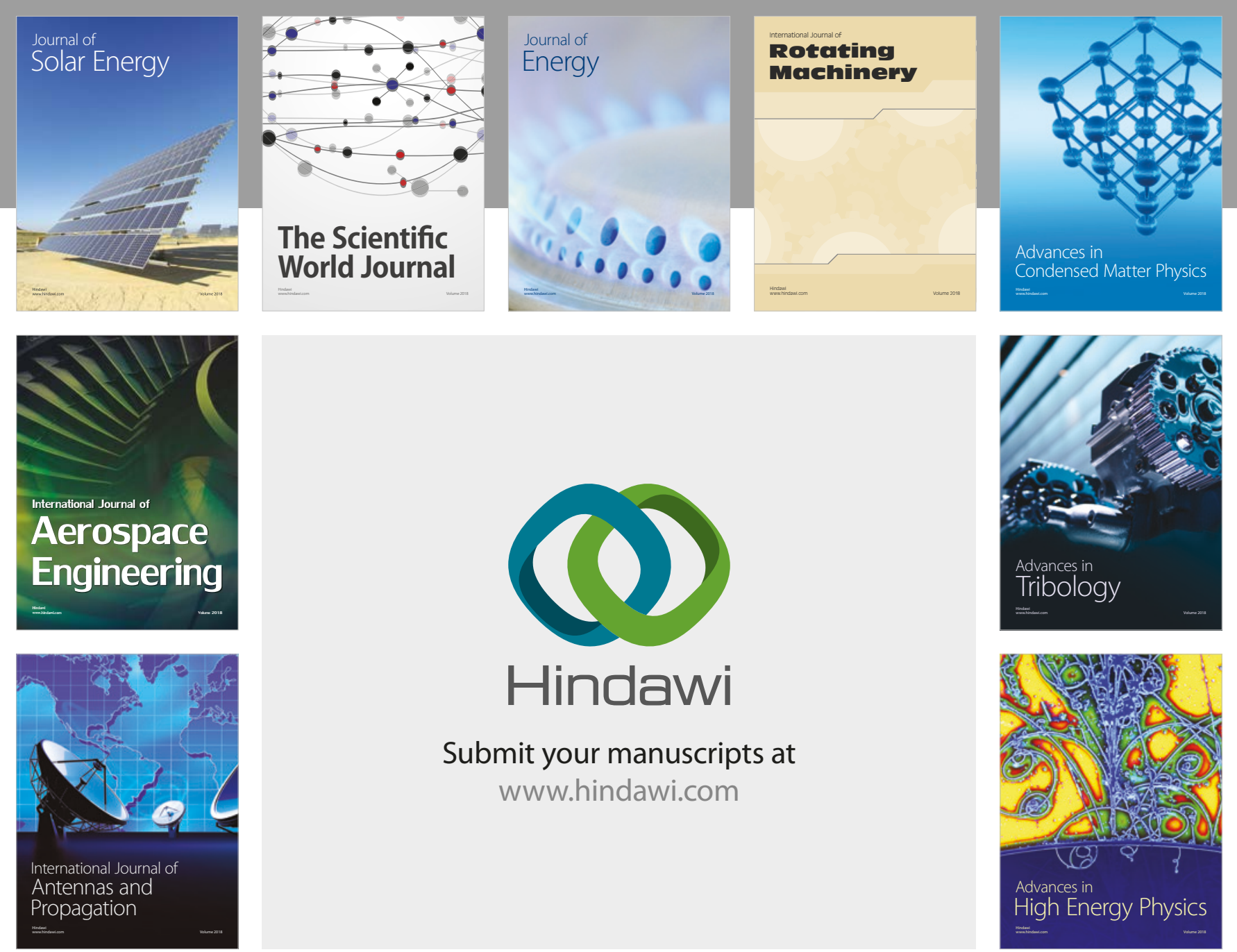

Submit your manuscripts at

www.hindawi.com
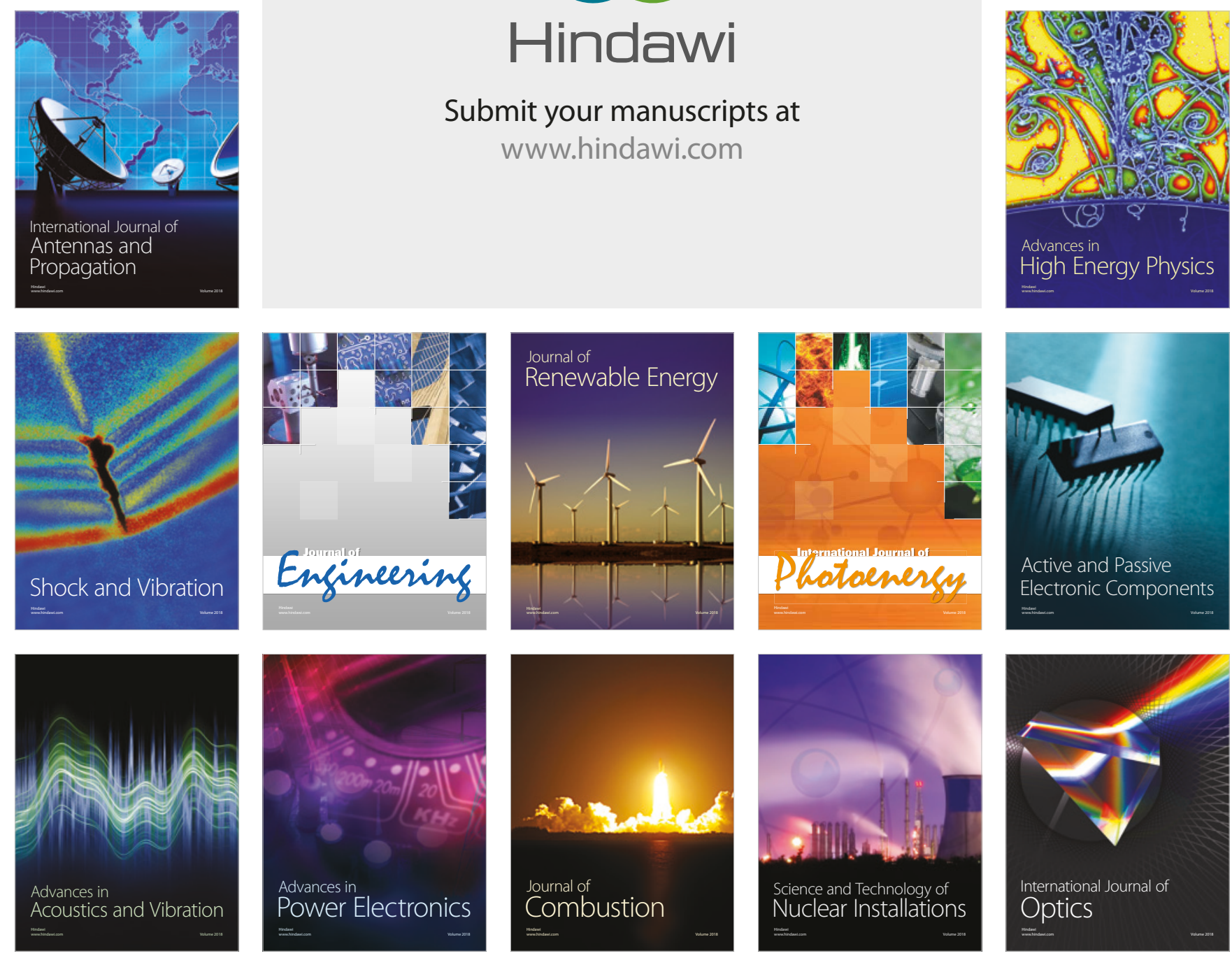